\title{
THE HUMAN SIGMOID- A STUDY IN SOUTH INDIAN CADAVERS
}

\author{
E. Venugopal1 ${ }^{1}$ Soorya Sridhar ${ }^{2}$, P. Kanagavalli ${ }^{3}$
}

${ }_{1}^{1}$ Assistant Professor, Department of Anatomy, Stanley Medical College, Chennai, Tamilnadu, India.

${ }^{2}$ Assistant Professor, Department of Anatomy, Government Medical College, Chennai, Tamilnadu, India.

${ }^{3}$ Associate Professor, Department of Anatomy, Government Medical College, Chennai, Tamilnadu, India.

\section{BACKGROUND}

ABSTRACT

Knowledge of sigmoid colon is of importance while treating patients with carcinoma of rectum. ${ }^{1}$ Sigmoid colon is often preferred as a site for colostomy. Mobility of sigmoid colon also makes it suitable for implantation of the ureter after surgical removal of bladder. Sigmoid colon shows great variation in its length giving rise to complications such as volvulus and diverticulitis, ${ }^{1}$ both of these conditions being common among Indian Population. Factors attributing to the condition include the length of the sigmoid colon, its position, the sigmoid mesocolon and its attachments. ${ }^{2}$ The study aims to record the morphometry of the sigmoid colon in both male and female cadavers of Chennai, and to correlate the morphometry with previous literature. We also wanted to reaffirm the relevance of the past morphometric literature with the current measurements with regard to region and biological gender.

\section{MATERIALS AND METHODS}

This is a descriptive study. 20 male and 10 female cadavers were dissected by first year M.B.B.S. students following standard dissection procedures and before the intestines were displaced, the study was conducted. Measurements were taken using inch tape and gross variations were noted and photographed.

\section{RESULTS}

$2 \%$ variation was observed with regard to relation to the site of the sigmoid colon. Various other measurements correlated with those of other previous studies. Previous studies show that irrespective of the dating of the studies, they are still relevant in current scenario to help and guide in invasive and surgical procedures of the sigmoid colon.

\section{CONCLUSION}

The relevance of previous studies irrespective of the decade of study has been established. Clinicians need to consider all the previous data for interventional procedures being done currently and should be planned on a daily basis.

\section{KEY WORDS}

Sigmoid Colon, Sigmoid Mesocolon, South India, Cadaveric Study, Morphology, Morphometry, Gross Anatomy

HOW TO CITE THIS ARTICLE: Venugopal E, Sridhar S, Kanagavalli P. The human sigmoid- a study in South Indian cadavers. J. Evolution Med. Dent. Sci. 2019;8(13):1013-1015, DOI: 10.14260/jemds/2019/225

\section{BACKGROUND}

Position and shape of the sigmoid colon varies according to the length of the colon, the length and mobility of its mesocolon. ${ }^{2}$ It forms a variable loop of about $40 \mathrm{cms}$ it lies normally in the lesser pelvis. ${ }^{1}$ If long, the sigmoid loop may arises out of the pelvic in the abdominal cavity \& lie in contact with loop of ileum..$^{2}$ The variations described in relation to its length is probably due to the differences in the actual extent as well as the variations in the length of the colon. The proximal and distal ends of sigmoid colon are occasionally joined together by a fibrous band which is usually associated with a narrow based sigmoid mesentery and may pre-dispose the sigmoid colon to torsion and volvulus. ${ }^{3}$

'Financial or Other Competing Interest': None.

Submission 25-10-2018, Peer Review 05-12-2018,

Acceptance 12-12-2018, Published 01-04-2019.

Corresponding Author:

Dr. Soorya Sridhar,

Assistant Professor, Department of Anatomy,

Government Medical College,

Omandurar Government Estate, Walajah Road,

Chennai-600002, Tamilnadu, India.

E-mail:dr.sooryasridhar@gmail.com

DOI: 10.14260/jemds/2019/225

\section{(c) $(\mathrm{i})($}

The rotation commonly occurs in a counter clock wise direction. Pronounced bands of peritoneum may also be found running from the proximal sigmoid colon to the posterior abdominal wall thereby restricting its mobility.

The development of acquired diverticula is also quite commonly seen in the sigmoid colon. ${ }^{3}$ The location of the diverticula is related to the under lying wall of colon. It commonly occurs midway between the anti-mesenteric and lateral taenia, where the wall is potentially weak not only because the circular muscle lacks the support of the longitudinal muscle, but also because it is traversed here by arteries as they access the submucosal vascular plexuses. ${ }^{3}$ Faecal material may become impacted in these diverticula, which subsequently become inflamed.

Invasive, Diagnostic Procedures requires a thorough understanding and knowledge of the normal morphology and morphometry of the Sigmoid Colon for accurate interpretation. ${ }^{4}$

\section{Aims and Objectives}

To record the morphometry of the sigmoid colon in both male and female cadavers of Chennai, and to correlate the morphometry with previous literature. We also wanted to reaffirm the relevance of the past morphometric literature 
with the current measurements with regard to region and biological gender.

\section{MATERIALS \& METHODS}

A descriptive study of Adult cadavers (Male 20, Female cadavers 10) following dissection as per standard guidelines followed by First M.B.B.S students during dissection in Stanley Medical College Chennai\& Government Medical College, Chennai.

\section{RESULTS}

\section{Variation}

Total number of variations is 1 out of 30 adult, sigmoid colon is attached $3 \mathrm{~cm}$ above the descending colon in adult female specimen. In this specimen length of sigmoid colon is $22 \mathrm{~cm}$. It starts from the left pelvic brim and ends at the recto sigmoid junction, at the level of $3^{\text {rd }}$ sacral vertebra. It is supplied by 3 sigmoid arteries which are the branches of inferior mesenteric artery. In its whole course it is not fixed to the midline and wall. There are no other extra peritoneal bands and adhesions are observed. It is observed that sigmoid colon is attached $3 \mathrm{~cm}$ above the descending colon.

The percentage of the variation is 2 per 100 specimens.

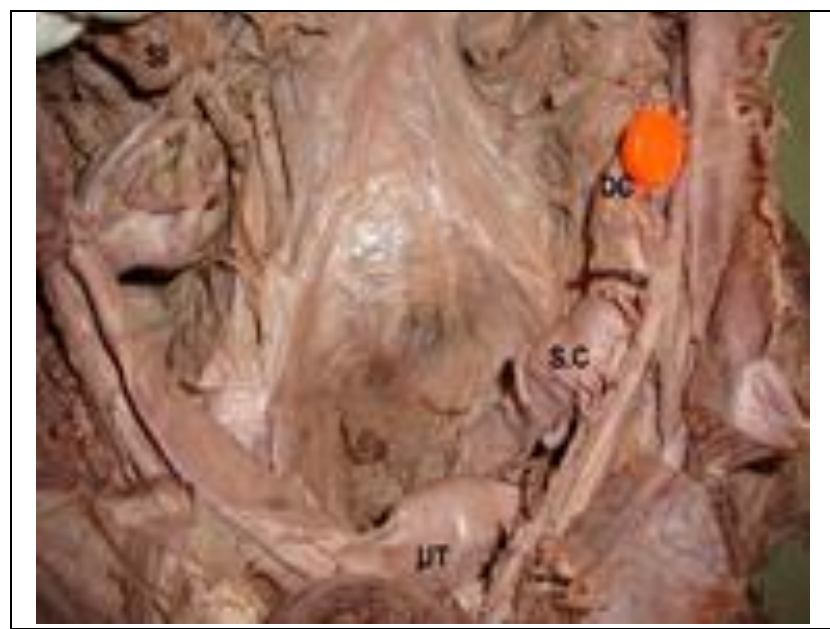

Figure 1. Sigmoid Colon Attached $3 \mathrm{~cm}$ Above the Descending Colon in Female Cadaver sc-sigmoid colon, si-small intestine

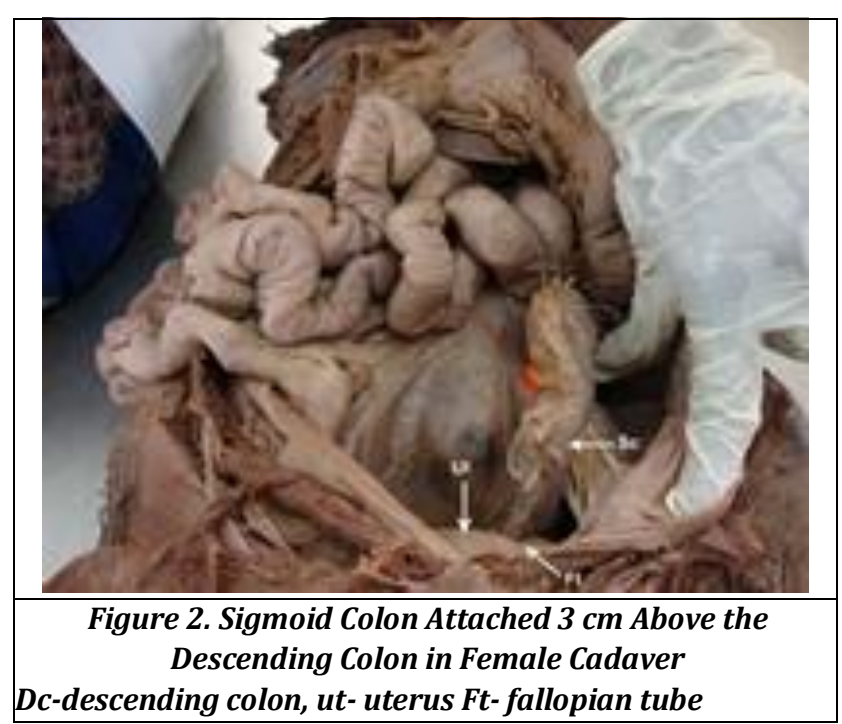

\begin{tabular}{|c|c|c|c|}
\hline Length (cm) & Max & Min & Average \\
\hline Male & 46 & 27 & 36.5 \\
\hline Female & 45 & 22 & 32.6 \\
\hline \multicolumn{4}{|c|}{ Table I. Average Length of Sigmoid Colon } \\
\hline
\end{tabular}

In the present study, the length along the anti-mesenteric border in male varies from $27-46 \mathrm{~cm}$. In 8/ 20 male the length varied from 33-38 cms., 7 are between $39 \mathrm{cms} .-46 \mathrm{cms}$. and 5 between $27-32 \mathrm{~cm}$. The average length of sigmoid colon along the anti-mesenteric border in male is observed to vary from $27-46 \mathrm{cms}$. whereas the average length in male is $36.5 \mathrm{cms}$. Whereas in females $6 / 10$, length between $22-32 \mathrm{cms}$., $3 / 10$ are having in between $39-46 \mathrm{cms}$., and $1 / 10$ is between 33-38 cms., whereas the average length in case of female is $32.6 \mathrm{cms}$..

\begin{tabular}{|c|c|c|}
\hline Length (cm) & No. & \% \\
\hline 22 to 32 & 6 & 60 \\
\hline 33 to 38 & 1 & 10 \\
\hline 39 to 46 & 3 & 30 \\
\hline \multicolumn{2}{|c|}{ Table II. Observations of Length of Sigmoid Colon in } \\
Female \\
\hline
\end{tabular}

Site and Shape

In all cases located in lesser pelvis \& S Shaped.

Sigmoid Mesocolon/Shape

Inverted 'v'-shaped.

\begin{tabular}{|c|c|c|c|c|c|c|}
\hline Length (cm) & \multicolumn{2}{|c|}{ Maximum } & \multicolumn{2}{c|}{ Minimum } & \multicolumn{2}{c|}{ Average } \\
\hline Limb & Right & Left & Right & Left & Right & Left \\
Male & 10 & 8 & 5 & 3 & 7.02 & 5.7 \\
\hline Female & 10 & 9 & 5 & 3 & 7.5 & 5.4 \\
\hline Table III. Length of Pelvic Mesocolon in Adults \\
\hline
\end{tabular}

\section{Length of Right Limb of Mesocolon}

Length of right limb in male and female varies from $10 \mathrm{cms}$. to $5 \mathrm{cms}$. The Average length of right limb in adult male is 7.02 cms. \&in female is $7.5 \mathrm{cms}$. Length of left limb in male varies between $8 \mathrm{cms}$. and $3 \mathrm{cms}$., in female between $9 \mathrm{cms}$. to $3 \mathrm{cms}$.

\begin{tabular}{|c|c|c|c|}
\hline & $\begin{array}{c}\text { Length Max } \\
\text { (cm) }\end{array}$ & $\begin{array}{c}\text { Length Min } \\
\text { (cm) }\end{array}$ & $\begin{array}{c}\text { Average } \\
\text { Width }(\mathbf{c m})\end{array}$ \\
\hline Male & 6 & 2 & 4.1 \\
\hline Female & 7 & 2 & 4.2 \\
\hline \multicolumn{3}{|c|}{ Table IV. Width of Sigmoid Mesocolon in Adults } \\
\hline
\end{tabular}

Width of mesocolon in adult male varies from $6 \mathrm{cms}$. to 2 cms.. Average width of sigmoid mesocolon in male is $4.1 \mathrm{cms}$. \& in female from $7 \mathrm{cms}$. to $2 \mathrm{cms}$.

\begin{tabular}{|c|c|c|c|}
\hline Sl. No. & Vertebral level & No. & \% \\
\hline 1 & $\begin{array}{c}\text { Corresponding with bifurcation of LCIA } \\
\text { and related with L5 }\end{array}$ & 27 & $90 \%$ \\
\hline 2 & $\begin{array}{c}\text { Corresponding with just above the } \\
\text { bifurcation of LCIA and related with L4 }\end{array}$ & 2 & $6.66 \%$ \\
\hline 3 & $\begin{array}{c}\text { Corresponding with just below the } \\
\text { bifurcation of LCIA and related with L5 }\end{array}$ & Nil & Nil \\
\hline 4 & $\begin{array}{c}\text { Corresponding with the middle of LCIA } \\
\text { and related with disc between L4 \& L5 }\end{array}$ & 1 & $3.34 \%$ \\
\hline $\begin{array}{c}\text { Table V. Relation of Apex of Sigmoid Mesocolon In } \\
\text { Adults. Corresponding with Bifurcation of Left } \\
\text { Common Iliac Artery }\end{array}$ \\
\hline
\end{tabular}




\section{DISCUSSION}

Length of sigmoid colon. In the present study average length of in male is 36.5 \& in female $32.6 \mathrm{cms}$.

\section{Shape of Sigmoid Colon}

\begin{tabular}{|c|c|c|}
\hline Name of The Author & Starting & Ending \\
\hline Grey's Anatomy & \multirow{6}{*}{$\begin{array}{l}\text { Pelvic Brim on } \\
\text { Left Side }\end{array}$} & \multirow{8}{*}{$\begin{array}{c}\text { In Front of } 3^{\text {rc }} \\
\text { Sacral } \\
\text { Vertebra }\end{array}$} \\
\hline Cunningham's Manual & & \\
\hline T.S. Ranganathan & & \\
\hline W. Henry Hollinshead & & \\
\hline Russell. T. Wood Burne & & \\
\hline Inderbir Singh & & \\
\hline $\begin{array}{c}\text { Barry. Janson Surgical } \\
\text { Anatomy }\end{array}$ & Iliac Crest & \\
\hline Present Study & $\begin{array}{l}\text { Pelvic Brim } \\
\text { on Left Side }\end{array}$ & \\
\hline Table VI. Loc & f Sigmoid Co & \\
\hline
\end{tabular}

\begin{tabular}{|c|c|}
\hline Name of Author & Length ( cm) \\
\hline Grey's Anatomy $^{3}$ & 40 \\
\hline Cunningham's Manual $^{2}$ & $16-80$ \\
\hline W. Henry Hollinshed & 40 \\
\hline T. S. Ranganathan & 40 \\
\hline B. D. Chourasia ${ }^{1}$ & 40 \\
\hline Inderbir Singh & 40 \\
\hline Present Study & 40 \\
\hline \multicolumn{2}{|c|}{ Table VII } \\
\hline
\end{tabular}

\begin{tabular}{|c|c|}
\hline Name of the Author & Shape \\
\cline { 1 - 1 } Grey's Anatomy & $\begin{array}{c}\text { Directed Initially } \\
\text { Downwards to Right } \\
\text { and Then } \\
\text { Downwards }\end{array}$ \\
\cline { 1 - 1 } T. S. Ranganathan & 's' Shape or $\sum$ Shape \\
\cline { 1 - 1 } Last's Anatomy Regional and Applied & Sinus Loop \\
\cline { 1 - 1 } Callender's Surgical Anatomy & 's' Shape. \\
\cline { 1 - 1 } W. Henry Hollinshead & \\
\hline B. D. Chourasia & Present Study \\
\hline \multicolumn{2}{|c|}{ Table VIII }
\end{tabular}

Shape \& direction of sigmoid colon described by all the authors resemble 'S' shape.

\section{Sigmoid Mesocolon}

In present study the shape of the sigmoid mesocolon is also in the form of inverted ' $v$ ' shape. The present study is coinciding with all the authors in shape and relations of the Apex and two limbs of the Mesocolon.

\section{CONCLUSION}

- Average length of sigmoid colon in male is $36.5 \mathrm{~cm}$ \& female is $32.6 \mathrm{~cm}$ (Male $4 \mathrm{~cm}>$ females)

- Shape of sigmoid colon is in the form of 's' shape in all the specimens.

- Sigmoid mesocolon in the form of inverted ' $v$ ' shape.

- It is observed that sigmoid colon is attached $3 \mathrm{~cm}$ above the descending colon in adult female body.

- The frequency of sigmoid volvulus is more in adult males when compared to adult females.

\section{REFERENCES}

[1] Chaurasia BD. BD Chaurasia's Human anatomy, regional and applied dissection and clinical head \& neck. $4^{\text {th }}$ edn. CBS Publishers 2007: p. 259.

[2] Cunningham's Manual of Practical Anatomy. 15th edn. Oxford University Press 2003: p. 145-6.

[3] Standring S. Gray's Anatomy: the anatomical basis of clinical practice. $39^{\text {th }}$ edn. Edinburgh, New York: Churchill Livingstone Elsevier Ltd., 2005: p. 119798.

[4] Madiba TE, Haffajee MR, Sikhosana MH. Radiological anatomy of the sigmoid colon. Surg Radiol Anat 2008;30(5):409-15. 